\title{
Epidemiological Study of Congenital Heart Defects in Children and Adolescents. Analysis of 4,538 Cases
}

\author{
Nelson Itiro Miyague, Silvia Meyer Cardoso, Fabrício Meyer, Frederico Thomaz Ultramari, \\ Fábio Henrique Araújo, Igor Rozkowisk, Alisson Parrilha Toschi
}

Curitiba, PR - Brazil

\begin{abstract}
Objective - To analyze the frequency and prevalence of congenital heart defects in a tertiary care center for children with heart diseases.

Methods - We carried out an epidemiological assessment of the firstmedical visit of 4,538 children in a pediatric hospital from January 1995 to December 1997. All patients with congenital heart defects had their diagnoses confirmed at least on echocardiography. The frequency and prevalence of the anomalies were computed according to the classification of sequential analysis. Age, weight, and sex were compared between the groups of healthy individuals and those with congenital heart defects after distribution according to the age group.
\end{abstract}

Results - Of all the children assessed, 2,017 (44.4\%) were diagnosed with congenital heart disease, 201 (4.4\%) with acquired heart disease, 52 (1.2\%) with arrhythmias, and 2,268 (50\%) were healthy children. Congenital heart diseases predominated in neonates and infants, corresponding to $71.5 \%$ of the cases. Weight and age were significantly lower in children with congenital heart defects. Ventricular septal defect was the most frequent acyanotic anomaly, and tetralogy of Fallot was the most frequent cyanotic anomaly.

Conclusion-Children with congenital heart defects are mainly referred during the neonatal period and infancy with impairment in gaining weight. Ventricular septal defect is the most frequent heart defect.

Keywords: congenital heart disease, epidemiology, prevalence

Hospital Infantil Pequeno Príncipe and Associação de Proteção à Infância Dr Raul Carneiro - Curitiba

Mailing address: Nelson Itiro Miyague - Rua Vivian Stec Toledo, 70 - 82300-740

- Curitiba, PR, Brazil - E-mail: cardiologia.clinica@hipp.com.br

English version by Stela Maris C. e Gandour
Congenital anomalies of the heart and great vessels are the most common severe congenital malformations ${ }^{1}$, and they have high mortality in the first year of life ${ }^{4}$. Several studies carried out with specific populations have had an incidence of between 2 and 10 per 1,000 live births. Based on a recent study in the city of Londrina, an incidence of 4/1,000 live births was estimated in the state of Paraná 5 .

This study aimed at establishing the frequency and prevalence of congenital heart anomalies in children referred to a tertiary care center of pediatric cardiology.

\section{Methods}

We retrospectively analyzed the medical records of 4,538 patients, who, from January 1995 to December 1997, sought the pediatric cardiology outpatient care unit of the Hospital Infantil Pequeno Príncipe, which is a tertiary center for the treatment of heart diseases in children and adolescents in the city of Curitiba, in the state of Paraná. Most patients were referred from the states of Paraná (86.1\%) and Santa Catarina (10.9\%).

All patients underwent clinical and electrocardiographic examinations, following a uniform protocol at the first medical visit. Chest radiography was performed in $75 \%$ of the children, and 3,302 (72.7\%) underwent echocardiography with color Doppler and spectral analysis at our service.

The patients were divided into 4 groups: 1 ) group Icomprising 2,268 (50\%) children whose cardiological assessment was considered normal; 2) group II - comprising 2,017 (44.4\%) patients with congenital heart defects; 3 ) group III - comprising 201 (4.4\%) patients with acquired heart disease; and 4) group IV - comprising $52(1.2 \%)$ patients with arrhythmias.

The diagnosis of a structural defect was based on the echocardiographic study. Based on this, 56 children in the congenital heart disease group were excluded from the analysis because they had not undergone echocardiography at our service. All group III patients had their diagnoses 
confirmed on echocardiography. Thirteen group IV children underwent only electrocardiography.

The following age groups were considered: neonates (1-30 days), infants (31 days to 2 years), preschool children (from 2 to 6 years), school children (from 6 to 12 years), and adolescents ( $>12$ years).

The classification was based on the sequential analysis of the heart performed on the echocardiogram, following the nomenclature of the European Paediatric Cardiac Code $^{6}$ and the Congenital Heart Surgery Nomenclature and Database Project ${ }^{7}$.

We considered a complex heart disease as a set of associated malformations necessary for maintenance of the patient's life, each of them receiving a specific name in the literature as follows: total anomalous pulmonary venous drainage, hypoplastic left heart syndrome, single ventricle, mitral atresia, pulmonary atresia with intact ventricular septum, tricuspid atresia, double right ventricular outflow tract, double left ventricular outflow tract, tetralogy of Fallot, truncus arteriosus, and transposition of the great vessels. Therefore, persistent ductus arteriosus, atrial septal defect, ventricular septal defect, and pulmonary stenosis were not considered independently when they were part of a complex heart disease and necessary for the patient's survival.

When a set of alterations did not have a specific name and their association was not required for the patient's life, the malformations were considered as associated diseases and computed alone.

The following anomalies were excluded from the analysis: the anomalies of position and laterality, the right aortic arch, peripheral pulmonary stenosis, and the bicuspid aortic valve. In the same way, functional alterations, such as mitral, tricuspid, aortic, and pulmonary insufficiencies were not considered in the analysis.

Categorical data are shown in absolute figures and percentages. The continuous variables are shown as mean, standard deviation, and median. The comparative study of the demographic variables was performed only between groups I (normal) and II (congenital heart diseases). Groups II and III had significantly fewer cases than the other groups. For comparison, the Student t test and the Kruskall Wallis test were used for continuous variables, and the chisquare test was used for qualitative variables. Data were computed and analyzed with EPI INFO software and were considered statistically significant when $\mathrm{p}<0.05$.

\section{Results}

Of the 4,482 patients studied, 1,961 (43.8\%) had congenital heart defects confirmed at least on color Doppler echocardiography (fig. 1). The distribution of the patients according to their age groups is shown in table I. Congenital heart defects were most frequently found among neonates and infants.

Patients with congenital heart defects had significantly lower age and weight than healthy children, $\mathrm{p}<0.0001$ and $p<0.0001$, respectively. No predominance of sex occurred in the group of congenital heart defcts. The male sex predominated slightly in the healthy group, but the female sex predominated in the other groups (tab. II).

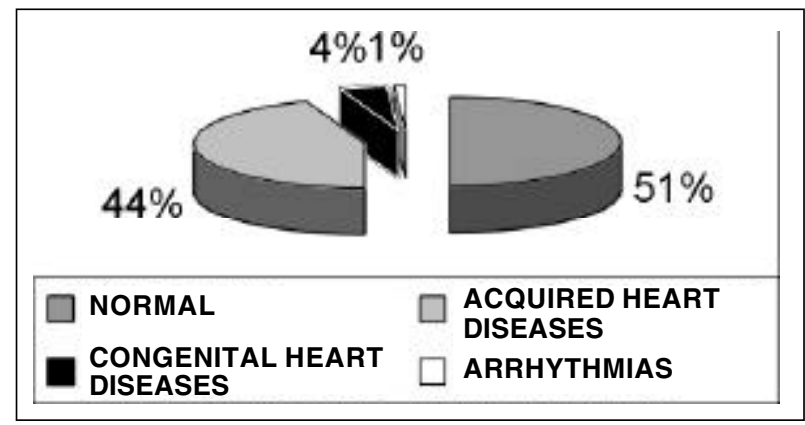

Fig. 1 - Distribution of the cases in the different groups.

\begin{tabular}{|lccccc|}
\hline \multicolumn{5}{c}{ Table I - Distribution of the number of cases according to age in the different groups } \\
\hline & & Group I & Group II & Group III \\
Age group & Total & Normal & Acquired & Group IV \\
Arrhythmia
\end{tabular}

\begin{tabular}{|c|c|c|c|c|c|}
\hline \multirow[b]{2}{*}{ Group } & \multicolumn{2}{|c|}{ Age (months) } & \multirow{2}{*}{$\begin{array}{l}\text { Sex } \\
\text { F/M }\end{array}$} & \multicolumn{2}{|c|}{ Weight (grams) } \\
\hline & Mean \pm SD & Median & & Mean \pm SD & Median \\
\hline Healthy & $64.2 \pm 49.2$ & 60 & $987 / 1281$ & $20.174 \pm 12.890$ & 18.050 \\
\hline Congenital & $25.9 \pm 40.2$ & 6.5 & 980/981 & $9.767 \pm 9.474$ & 5.900 \\
\hline Acquired & $83.5 \pm 59.2$ & 96 & $101 / 99$ & $22.776 \pm 14.032$ & 23.000 \\
\hline Arrhythmias & $70.3 \pm 57.3$ & 70.4 & $30 / 22$ & $20.506 \pm 13.312$ & 19.800 \\
\hline
\end{tabular}




\begin{tabular}{|c|c|c|c|}
\hline Anomaly & $\mathrm{n}$ & Frequency $\mathrm{X} / 100$ & Prevalence X/ 1000 \\
\hline \multicolumn{4}{|l|}{ Atria and great vessels } \\
\hline - Partial anomalous pulmonary venous drainage & 12 & 0.6 & 2.7 \\
\hline - Total anomalous pulmonary venous drainage & 39 & 2 & 8.7 \\
\hline - Cor triatriatum & 4 & 0.2 & 0.9 \\
\hline - Single atrium & 6 & 0.3 & 1.3 \\
\hline - Atrial septal defect & 375 & 19.1 & 83.7 \\
\hline \multicolumn{4}{|l|}{ Atrioventricular connection } \\
\hline - Mitral atresia & 8 & 0.4 & 1.8 \\
\hline - Tricuspid atresia & 45 & 2.3 & 10 \\
\hline - Single ventricle & 25 & 1.3 & 5.6 \\
\hline \multicolumn{4}{|l|}{ Ventriculoarterial connection } \\
\hline - Transposition of the great vessels & 81 & 4.1 & 18.1 \\
\hline - Double right ventricular outflow tract & 43 & 2.2 & 9.6 \\
\hline - Double left ventricular outflow tract & 2 & 0.1 & 0.5 \\
\hline - Truncus arteriosus & 20 & 1 & 4.5 \\
\hline \multicolumn{4}{|l|}{ Atrioventricular and ventriculoarterial connections } \\
\hline - Corrected transposition of the great vessels & 11 & 0.6 & 2.5 \\
\hline \multicolumn{4}{|l|}{ Atrioventricular valves } \\
\hline - Ebstein disease & 24 & 1.2 & 5.4 \\
\hline - Mitral valve prolapse & 26 & 1.3 & 5.8 \\
\hline \multicolumn{4}{|l|}{ Atrioventricular septum } \\
\hline - Partial atrioventricular septal defect & 9 & 0.5 & 2 \\
\hline - Total atrioventricular septal defect & 109 & 5.6 & 24.3 \\
\hline \multicolumn{4}{|l|}{ Ventricles } \\
\hline - Hypoplastic left ventricle syndrome & 15 & 0.8 & 3.4 \\
\hline \multicolumn{4}{|l|}{ Ventricular septum } \\
\hline - Ventricular septal defect & 598 & 30.5 & 133.5 \\
\hline \multicolumn{4}{|l|}{ Right ventricular outflow tract } \\
\hline - Infundibular pulmonary stenosis & 2 & 0.1 & 0.5 \\
\hline - Pulmonary valve stenosis & 222 & 11.3 & 49.5 \\
\hline - Pulmonary atresia with intact ventricular septum & 13 & 0.7 & 2.9 \\
\hline \multicolumn{4}{|l|}{ Left ventricular outflow tract } \\
\hline - Asymmetric septal hypertrophy & 2 & 0.1 & 0.5 \\
\hline - Fixed subaortic stenosis & 23 & 1.2 & 5.1 \\
\hline - Aortic valve stenosis & 69 & 3.5 & 15.4 \\
\hline \multicolumn{4}{|l|}{ Tetralogy of Fallot and variant } \\
\hline - Tetralogy of Fallot & 136 & 6.9 & 30.5 \\
\hline - Pulmonary atresia with ventricular septal defect & 16 & 0.8 & 3.6 \\
\hline \multicolumn{4}{|l|}{ Coronary arteries } \\
\hline - Anomalous left coronary origin & 1 & 0.1 & 0.2 \\
\hline \multicolumn{4}{|l|}{ Aorta, pulmonary artery and great vessels } \\
\hline - Aorto-pulmonary window & 1 & 0.2 & 0.2 \\
\hline - Pulmonary trunk stenosis & 334 & 17 & 74.5 \\
\hline - Supravalvular aortic stenosis & 4 & 0.2 & 0.9 \\
\hline - Interruption of the aortic arch & 9 & 0.4 & 2 \\
\hline - Coarctation of the aorta & 4 & 0.2 & 0.9 \\
\hline - Coarctação da aorta & 123 & 6.3 & 17.5 \\
\hline - Double aortic arch & 7 & 0.4 & 1.6 \\
\hline - Anomalous origin of the right subclavian artery & 8 & 0.4 & 1.8 \\
\hline
\end{tabular}

Frequency and prevalence of congenital heart defects are detailed in table III. Complex heart defects were found in 439 patients, and associations of anomalies were found in 538 patients. The most frequent acyanotic congenital heart defects were as follows: ventricular septal defect (30.5\%), atrial septal defect $(19.1 \%)$, persistent ductus arteriosus (17\%), pulmonary valve stenosis (11.3\%), and coarctation of the aorta $(6.3 \%)$. The most frequent cyanotic congenital heart defects were as follows: tetralogy of Fallot (6.9\%), transposition of the great vessels $(4.1 \%)$, tricuspid atresia $(2.3 \%)$, and total anomalous pulmonary venous drainage (2\%).

Of the acyanotic congenital heart defects, ventricular septal defect and coarctation of the aorta were most frequently associated with other anomalies, which were significantly more common in the presence of coarctation of the aorta, $\mathrm{p}<0.01$. Atrial septal defect, persistent ductus arteriosus, and pulmonary stenosis predominated as isolated diseases, but no significant difference was observed between them (fig. 2).

\section{Discussion}

Cardiac anomaly is the most frequent congenital malformation and is mainly associated with genetic or 


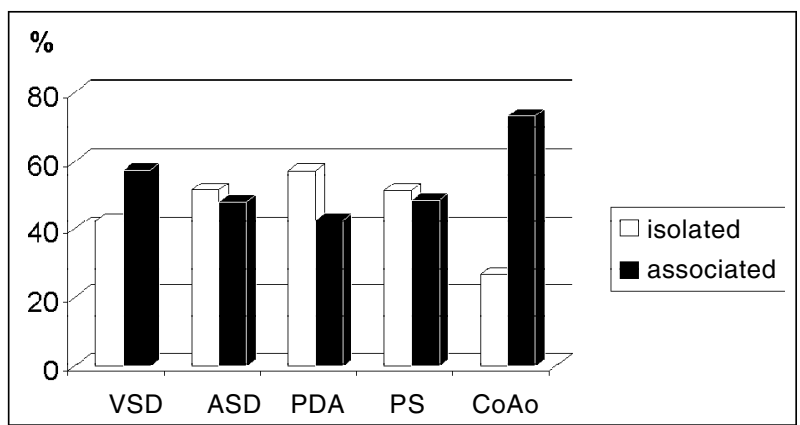

Fig. 2 - Distribution of the most frequent acyanotic heart defects associated or not with other heart diseases.

chromosomal alterations. Its clinical manifestation fundamentally depends on the hemodynamic repercussion and usually exteriorizes in the first year of life. Autopsy studies show that the greatest mortality occurs at this age ${ }^{2-4}$.

A study of infants below the age of 1 year at the Royal Brompton Hospital, in England, showed that most infants hospitalized were neonates ${ }^{8}$.

In our study, most children with congenital heart disease were infants followed by neonates. Even considering that our evaluation concerns patients at the outpatient care unit and that carried out at the Royal Brompton Hospital analyzed hospitalized children, we observe a difference regarding the time of referral of the patients.

With us, the predominance of the diagnosis of congenital heart disease in infants coincided with the clinical manifestation of shunt heart defects with pulmonary venocapillary hypertension, such as ventricular septal defect and persistent ductus arteriosus, which were prevalent in our study. We should consider, however, that in our study, many children came from the countryside or other states, and this may have delayed their access to a specialized center.

Complex defects, which prevailed in other studies ${ }^{7-11}$, manifesting in the first days of life, such as hypoplastic left ventricle and transposition of the great vessels, were less frequently found among us. Because these patients die early, we may suppose that many cannot receive specialized care in time or may even die without a diagnosis.

Delay in weight gain is significant considering that the control group belongs to the same population of children. The hemodynamic repercussion may have influenced this difference.

Children with congenital heart disease with great leftto-right shunt, heart failure, and pulmonary hypertension usually have growth delay. The degree of hypoxia, however, does not show a linear correlation with the degree of impairment ${ }^{12}$.

Epidemiological studies have shown varied frequency and prevalence of congenital heart diseases. The technological advance and routine use of echocardiography have contributed to improvement in the establishment of the diagnosis, and, therefore, to increase the prevalence of some heart defects. Ventricular septal defect is the most dramatic example in recent studies, with a frequency of $41.6 \%$ in the study by Samánek and Vorísková ${ }^{11}$ versus $15.7 \%$ in the NERICP series ${ }^{10}$.

Ventricular septal defect, with an incidence of $30.5 \%$, was the most common defect in our study, similarly to the results of other studies. That incidence was lower than the incidence reported in recent studies, $41.59 \%{ }^{11}$ and $39 \%{ }^{13}$, but higher than the incidence reported in older studies, $15.4 \%^{8}$ and $15.7 \%{ }^{10}$. Factors, such as the cross-sectional analysis of the cases, the gold standard of the diagnosis, the spontaneous closure of the lesion, and the nonrecognition of minimum or small septal defects by the physician responsible for primary care, may have contributed to the difference between our figures and those in the literature.

Atrial septal defect $(19.1 \%)$, persistent ductus arteriosus $(17 \%)$, and pulmonary stenosis $(11.3 \%)$ were the most frequent anomalies, with an incidence greater than $10 \%$. A lower frequency has been reported in the literature, because those anomalies have been classified in a secondary hierarchical scale, and have been usually associated with other anomalies.

Coarctation of the aorta, the fifth most frequent anomaly in this study, has a high degree of association with other anomalies and shows frequency similar to that in the study by Samánek and Vorísková ${ }^{11}$. Aortic valve stenosis, the third anomaly in the study by those authors, had a low prevalence in our study, but a prevalence similar to that reported in other studies $9,10,14$.

In regard to cyanotic heart defects, tetralogy of Fallot $(6.9 \%)$, transposition of the great vessels $(4.1 \%)$, and tricuspid atresia $(2.3 \%)$ were the most frequent anomalies. According to the literature, the most prevalent anomaly is transposition of the great vessels, with an incidence ranging from 3.5 to $10.9 \%$ 9,14.

Data collection was based on a uniform protocol of patient's assistance, but performed in a retrospective manner, which significantly limits its interpretation. By choosing echocardiography as the gold standard, some cases that had been previously considered mild or had been ignored were computed. However, the echocardiographies at the Hospital Infantil Pequeno Príncipe were performed by several members of the clinical team and not specifically by an echocardiographer, which may lead to different interpretations of the same defect.

In conclusion, congenital heart defects are mainly referred for treatment during infancy and the neonatal period, ventricular septal defect being the most frequent anomaly. Complex heart defects with high mortality in the first days of life had a lower prevalence than that reported in the literature, suggesting that, among us, these cases have not reached adequate care in time. Other studies should be carried out to confirm these numbers and to stimulate continuous medical education to improve the prognosis of these patients. Impairment of ponderal development requires better evaluation and orientation by us. 


\section{References}

1. Hoffman JIE, Christianson R. Congenital heart disease in a cohort of 19.502 births with long-term follow-up. Am J Cardiol 1978; 42: 641-7.

2. Hegerty AS, Anderson RH, Ho SY. Congenital heart malformations in the first year of life - a necropsy study. Br Heart J 985; 54: 583-92.

3. Vesterby A, Nielsen K, Borg L, Paulsen S, Baandrup U. Congenital heart malformations in Jutland, Denmark: a three year necropsy study in children aged 0-14 years. Br Heart J 1987; 58: 653-8.

4. Samánek M, Benešová D, Goetzová J, Hrycejová I. Distribution of age at death in children with congenital heart disease who died before the age of 15 . Br Heart J 1988; 59: 581-5.

5. Guitti JCS. Aspectos epidemiológicos das cardiopatias congênitas em Londrina, Paraná. Arq Bras Cardiol 2000; 74: 395-9.

6. Franklin RCG, Anderson RH, Daniëls O, Elliot M, et al. Report of the Coding Committee of the Association for European Paediatric Cardiology. Cardiol Young 1999; 9: 633-57.

7. Mavroudis C, Jacobs JP. Congenital heart surgery nomenclature and database project: overview and minimum dataset. Ann Thorac Surg 2000; 59: S2-17.

8. Scott DJ, Rigby ML, Miller GAH, Shinebourne EA. The presentation of symptomatic heart disease in infancy based on 10 years' experience (1973-82). Implications for the provision of services. Br Heart J 1984; 52: 248-57.

9. Moller JH, Moodie DS, Blees M, Norton JB, Nouri S. Symptomatic heart disease in infants: comparison of three studies performed during 1969-1987. Pediatr Cardiol 1995; 16: 216-22.

10. Fyler DC, Buckley LP, Hellenbrand WE, Cohn HE. Report of the New England Regional Infant Program. Pediatrics 1980; 65: 375-461.

11. Samánek M, Vorísková M. Congenital heart disease among 815,569 children born between 1980 and 1990 and their 15-year survival: a prospective Bohemia survival study. Pediatr Cardiol 1999; 20: 411-7.

12. Feldt RH, Strickle Gl, Weidman WH. Growth of children with heart disease. Am J Dis Child 1969; 117: 573-9.

13. Bosi G, Scorrano M, Tosato G, Forini E, Chakrokh R and the Working Party of the Italian Society of Pediatric Cardiology. The Italian Multicentric Study on epidemiology of congenital heart disease: first step of the analysis. Cardiol Young 1999; 9: 291-9.

14. Fixler DE, Pastor P, Chamberlin M, Sigman E, Eifler CW. Trends in congenital heart disease in Dallas County births 1971-1984. Circulation 1990; 81: 137-42. 